PENGARUH MODEL PEMBELAJARAN STUDENT

FACILITATOR AND EXPLAINING (SFAE) TERHADAP HASIL

BELAJAR SISWA PADA MATERI SISTEM GERAK PADA

MANUSIA KELAS XI IPA MA NEGERI TANA TORAJA

\author{
Hidayah Sabo'1 \\ Nurul Fadhilah" ${ }^{*}$ \\ 1,2 Prodi Pendidikan Biologi, FKIP, Universitas Muhammadiyah Makassar, Indonesia \\ hidayahsabo749@gmail.com ${ }^{1)}$ \\ nurul.fadhilah@unismuh.ac.id ${ }^{2 *}$
}

\begin{abstract}
Abstrak
Tujuan dari penelitian ini yaitu: 1) untuk mengetahui hasil belajar siswa kelas XI IPA MA Negeri Tana Toraja dengan penerapan model pembelajaran Student Facilitator And Explaining (SFAE) pada materi sistem gerak pada manusia, 2) untuk mengetahui ada tidaknya pengaruh model pembelajaran Student Facilitator And Explaining ( $S F A E$ ) terhadap hasil belajar siswa pada materi sistem gerak pada manusia kelas XI IPA MA Negeri Tana Toraja. Jenis penelitian ini adalah quasi eksperimen dengan desain nonequivalent control group design. Populasi dalam penelitian ini adalah seluruh siswa Kelas XI IPA MA Negeri Tana Toraja yang terdiri dari 2 kelas dengan jumlah 31 orang. Teknik pengambilan sampel pada penelitian ini menggunakan teknik sampling jenuh. Pengumpulan data penelitian ini menggunakan tes dan wawancara, sedangkan teknik analisis data penelitian ini menggunakan $t$-test. Hasil penelitian menunjukkan terdapat pengaruh penerapan model pembelajaran Student facilitator and explaining (SFAE) terhadap hasil belajar biologi siswa yang dibuktikan dengan hasil uji rata-rata nilai kelas kontrol lebih rendah dari kelas eksperimen yaitu $29<54,56$ dan berdasarkan nilai Sig (2-tailed) $>\alpha$ adalah $0,000<0,05$, sehingga dapat disimpulkan bahwa penerapan model pembelajaran Student facilitator and explaining (SFAE) memiliki pengaruh terhadap hasil belajar biologi siswa pada materi sistem gerak pada manusia kelas XI IPA MA Negeri Tana Toraja.
\end{abstract}

Kata Kunci: Student Facilitator And Explaining (SFAE), Hasil Belajar

Published by:

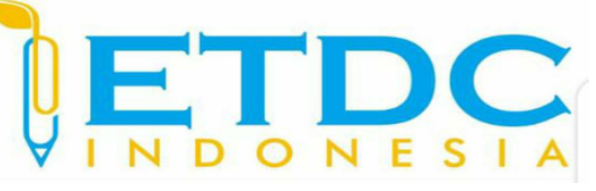

Copyright (C) 2021 The Author (s)

This article is licensed under CC BY 4.0 License

(cc) $\mathrm{BY}$ 


\section{PENGARUH MODEL PEMBELAJARAN STUDENT FACILITATOR AND EXPLAINING (SFAE) TERHADAP HASIL BELAJAR SISWA PADA MATERI SISTEM GERAK PADA MANUSIA KELAS XI IPA MA NEGERI TANA TORAJA}

\section{Pendahuluan}

Kualitas pembelajaran di sekolah pada dasarnya dinilai dari prestasi belajar siswa. Menurut Hamalik (2012), hasil belajar disebut juga sebagai perubahan tingkah laku yang mencakup kemampuan kognitif, afektif, dan psikomotorik. Hasil belajar yang tinggi merupakan tolak ukur keberhasilan seorang guru dalam menyampaikan materi pembelajaran. Selain itu, guru diharapkan mampu mengelola kelas dengan baik agar proses pembelajaran dapat berjalan dengan maksimal.

Dalam proses pembelajaran, guru bertindak sebagai fasilitator dan siswa sebagai student centered, yaitu siswa lebih aktif dibandingkan guru. Salah satu tugas seorang guru yaitu menghadirkan suasana belajar yang menyenangkan bagi seluruh siswa. Suasana kelas yang tidak menyenangkan akan membuat proses pembelajaran tidak berjalan dengan optimal (Riyandi et al., 2021). Guru menciptakan suasana belajar yang kondusif agar siswa terdorong untuk aktif selama proses pembelajaran berlangsung. Hal ini akan berdampak pada hasil belajar siswa yang tinggi, dengan kata lain tujuan pembelajaran telah tercapai (Khausar, 2014).

Berbagai upaya dilakukan guru untuk meningkatkan motivasi siswa serta turut aktif selama proses pembelajaran. Salah satunya yaitu menggunakan model pembelajaran yang sesuai dengan materi yang diajarkan. Penggunaan model pembelajaran yang tepat akan memudahkan siswa dalam menerima materi ajar, berani menyampaikan pendapat serta siswa terdorong untuk lebih aktif selama proses pembelajaran berlangsung. Siswa yang awalnya hanya duduk mendengarkan materi akan lebih termotivasi, terlibat langsung serta aktif ketika diskusi kelompok. Menurut Zahara (2018), penggunaan model pembelajaran yang kurang sesuai akan mempengaruhi hasil belajar siswa, siswa cenderung tidak aktif serta guru lebih mendominasi kelas padahal peran guru hanyalah sebagai fasilitator.

Hasil observasi di MA Negeri Tana Toraja memperlihatkan bahwa selama ini guru telah menerapkan metode pembelajaran yang bervariasi seperti ceramah, tanya jawab, dan diskusi. Namun hasil belajar siswa tetap kurang maksimal, hasil yang diperoleh yaitu sekitar $40 \%$ tuntas dan 60\% tidak tuntas dari nilai KKM yang telah ditetapkan yaitu 75. Hal tersebut dikarenakan masih banyak siswa yang tidak aktif selama pembelajaran, tidak berani menngemukakan pendapat, ada juga siswa yang kesulitan dalam menerima dan memahami pelajaran serta 
kurangnya interaksi antara siswa selama proses pembelajaran berlangsung.

Salah satu solusi yang dilakukan untuk mengoptimalkan hasil belajar siswa yaitu dengan menggunakan model pembelajaran yang tepat dan sesuai dengan karakteristik siswa dikelas. Salah satu model yang sesuai untuk diterapkan yaitu Student Facilitator And Explaining (SFAE). Menurut Prihatiningtyas dan Maryam (2019), model pembelajaran Student Facilitator And Explaining merupakan model inovatif yang menekankan siswa untuk aktif dan belajar untuk mempresentasikan pendapatnya kepada siswa yang lainnya. Hal ini sejalan dengan pendapat Rianti \& Nulhakim (2017), yaitu model Student Facilitator And Explaining (SFAE) dapat menumbuhkan kemampuan pemahaman konsep siswa karena guru menyampaikan materi didepan siswa dan memberikan kesempatan kepada siswa untuk menjelaskan kembali materi tersebut kepada teman kelasnya. Model ini sama dengan model inovatif lainnya yang lebih menekankan siswa untuk berpikir aktif untuk memperoleh hasil belajar yang lebh baik.

Model Student Facilitator And Explaining (SFAE) menekankan siswa untuk belajar lebih aktif serta memiliki kemampuan berkomunikasi yang baik dengan temannya. Selain itu, siswa akan termotivasi untuk belajar lebih giat, mampu berkomukasi dengan baik dan memiliki rasa tanggungjawab yang tinggi, siswa tidak merasa kesulitan dalam memahami materi dan kemampuan daya hafalnya meningkat (Zahara, 2018).

Keunggulan dari model SFAE adalah siswa mampu berpikir secara aktif dan kreatif, sehingga menghasilkan gagasan yang lebih baik dan lebih menarik. Hal tersebut dapat meningkatkan rasa percaya diri siswa. Selain itu, siswa memiliki kemampuan untuk mengemukakan ide untuk bertukar pendapat ketika memecahkan masalah (Alpindo, 2020).

Menurut Huda dalam Nopiana (2020), sintaks model pembelajaran Student Facilitator And Explaining (SFAE) adalah:

1) Guru memaparkan tujuan yang akan dicapai.

2) Guru menyajikan materi pelajaran

3) Guru memberikan kesempatan kepada siswa untuk menjelaskan kembali materi melalui bagan atau peta konsep.

4) Guru membuat kesimpulan dari ide atau pendapat siswa

Kelebihan lain dari model ini yaitu dapat meningkatkan motivasi siswa untuk memaparkan materi pelajaran, materi yang dipaparkan jelas dan dilakukan melalui demonstrasi sehingga dapat meningkatkan daya serap siswa. Selain kelebihan, model ini juga memiliki kekurangan misalnya siswa yang pemalu terkadang tidak mau mengikuti perintah guru ketika diinstruksikan untuk mendemonstrasikan materi, serta tidak semua siswa mendapatkan kesempatan untuk menjelaskan kembali materi ajar kepada temannya karena waktu pelajaran 
yang terbatas (Shoihim, 2014).

Berdasarkan uraian diatas maka penulis tertarik untuk mengadakan penelitian tentang "Pengaruh Model Pembelajaran Student Facilitator And Explaining (SFAE) terhadap hasil belajar siswa pada materi sistem gerak pada manusia kelas XI IPA MA Negeri Tana Toraja”.

\section{Metode Penelitian}

Metode yang digunakan pada penelitian ini yaitu metode quasi eksperimen yang merupakan pengembangan dari true experimental design. Metode ini digunakan untuk mengetahui hubungan sebab akibat atau pengaruh dari variabel terikat (Sugiyono, 2017). Desain penelitian yang digunakan adalah nonequivalent control group design, dimana kelompok eksperimen maupun kelompok kontrol tidak dipilih secara random atau acak.

Populasi pada penelitian ini adalah seluruh siswa Kelas XI IPA MA Negeri Tana Toraja, sedangkan sampel terpilih yaitu seluruh siswa kelas XI IPA MA Negeri Tana Toraja dengan jumlah siswa sebanyak 31 orang. Mengingat penelitian ini bersifat quasi eksperimen maka kedua kelas dipilih tanpa randomisasi namun menggunakan teknik sampling jenuh yaitu seluruh anggota dari populasi dijadikan sebagai sampel penelitian. Adapun jumlah sampel untuk setiap kelas adalah Kelas XI IPA 1 sebanyak 16 siswa sebagai kelas eksperimen dan kelas XI IPA 2 sebanyak 15 siswa sebagai kelas kontrol.

Teknik pengumpulan data adalah cara yang dilakukan untuk mendapatkan data yang mendukung terlaksananya suatu penelitian. Teknik dalam penelitian ini menggunakan metode tes dan non tes. Metode tes yang digunakan berupa pretest dan posttest dengan menggunakan soal pilihan ganda sebanyak 30 nomor soal, sedangkan metode non tes berupa observasi. Teknik analisis data yang digunakan yaitu analisis statistik deskriptif dan analisis statistik inferensial

\section{Hasil dan Pembahasan}

Pelaksanaan penelitian ini menggunakan dua kelas yaitu Kelas XI IPA 1 sebagai kelas eksperimen dengan jumlah siswa 16 orang dan Kelas XI IPA 2 merupakan kelas kontrol dengan jumlah siswa 15 orang. Kedua kelas tersebut diajarkan materi yang sama yaitu materi sistem gerak pada manusia dengan menggunakan model yang berbeda. Dimana kelas eksperimen diberikan perlakuan dengan menerapkan model pembelajaran Student Facilitator And Explaining (SFAE) sedangkan kelas kontrol diterapkan model pembelajaran konvensional atau pembelajaran yang berpusat pada guru.

Data pada penelitian diperoleh melalui tes yaitu pre-test dan post-test dengan jumlah masing-masing 30 butir soal pilihan ganda. Penyajian awal data dengan menggunakan statistik 
deskriptif kelas kontrol dan kelas eksperimen dalan penelitian ini dapat dilihat dalam bentuk Tabel 1 di bawah ini.

Tabel 1. Data statistik deskriptif hasil belajar Biologi kelas kontrol dan kelas eksperimen

\begin{tabular}{ccccc}
\hline \multirow{2}{*}{$\begin{array}{c}\text { Statistik } \\
\text { deskriptif }\end{array}$} & \multicolumn{2}{c}{ Kelas Kontrol } & \multicolumn{2}{c}{ Kelas eksperimen } \\
\cline { 2 - 5 } & Pretest & Posttest & Pretest & Posttest \\
\hline Skor Minimum & 16 & 40 & 12 & 75 \\
Skor Maksimum & 67 & 80 & 60 & 95 \\
Rata-rata & 33,80 & 62,80 & 29,94 & 84,50 \\
Standar Deviasi & 13,54 & 18,68 & 12,01 & 7,97 \\
\hline
\end{tabular}

Tabel 1 menunjukkan perbandingan antara kelas kontrol dan kelas eksperimen. Pada kelas kontrol, nilai pretes menunjukkan nilai rata-rata 33,80 dan simbangan baku 13,54, sedangkan pada kelas eksperimen nilai pretest menunjukkan nilai rata-rata 29,94 dan simbangan baku 12,01. Selanjutnya nilai posttest pada kelas kontrol menunjukkan nilai ratarata 62,80 dan simpangan baku 18,68 , sedangkan kelas eksperimen menunjukkan nilai rata-rata 84,50 dan simpangan baku 7,97. Sebelum menjawab hipotesis penelitian, terlebih dahulu dilakuakan uji persayaratan yaitu uji normalitas dan homogenitas. Uji normalitas pada penelitian ini menggunakan uji kolmogorov smornov yang bertujuan untuk mengetahui data posttest pada kedua kelas berdistribusi normal. Data hasil belajar kelas eksperimen dan kelas kontrol memiliki sig $>0,05$, maka dapat ditarik kesimpulan bahwa data tersebut berdistribusi normal. Selanjutnya uji homogenitas menggunakan uji anova dengan bantuan SPSS 25, uji ini bertujuan untuk mengetahui dua atau lebih kelompok data sampel berasal dari populasi yang memiliki variansi yang sama. Uji N-gain pada kelas eksperimen menunjukkan rata-rata sebesar 0,78 yang termasuk kategori tinggi, sedangkan kelas kontrol sebesar 0,40 dan termasuk kategori sedang. Adapun pengujian hipotesis pada penelitian ini dilakukan dengan menggunakan Independet Sample Test dengan bantuan program SPSS 25.0, maka didapat nilai signifikansi sebesar $0,000<0,05$.

Berdasarkan hasil analisis tersebut, diketahui terdapat perbedaan nilai pretest dan posttest antara kelas eksperimen dan kelas kontrol sehingga dapat disimpulkan bahwa kelas yang diberikan perlakuan model pembelajaran SFAE dapat meningkatkan hasil belajar siswa kelas XI IPA MA Negeri Toraja Utara. Pembelajaran dengan menggunakan model Student Facilitator And Explaining (SFAE) menunjukkan beberapa perubahan terhadap aktivitas siswa selama mengikuti pembelajaran. Peningkatan hasil belajar siswa terlihat dari perubahan- 
perubahan yang diamati selama pembelajaran melalui lembar observasi.

Perubahan aktivitas siswa yang dimaksud yaitu meningkatnya partisipasi siswa ketika proses pembelajaran berlangsung. Dengan penerapan model pembelajaran Student Facilitator And Explaining (SFAE), siswa lebih fokus dan tertarik terhadap materi pelajaran yang disampaikan oleh guru. Siswa juga sangat antusias dan aktif ketika diskuis kelompok dan siswa sudah berani untuk menyampaikan pendapatnya. Sejalan dengan Nopiana \& Mutaqin (2020) tentang kegiatan siswa di kelas dengan diberikan perlakuan Student Facilitator And Explaining (SFAE), siswa menjadi lebih aktif selama mengikuti diskusi kelompok, mengemukakan pendapat serta merespon pendapat siswa lainnya.

Selanjutnya menurut Mustikasari et al, (2019), siswa yang dikelompokkan dengan temannya akan menjalin interaksi yang baik dan akan mendukung tumbuh kembangnya untuk belajar dan berpartisipasi dengan aktif dalam proses pembelajaran. Selain itu, siswa akan memperoleh pengalaman dan kesempatan untuk saling bertukar informasi, berkomunikasi dengan baik serta belajar bersama sehingga proses pembelajaran menjadi menyenangkan.

Model Student Facilitator And Explaining (SFAE) merupakan salah satu model yang menuntut siswa untuk aktif, oleh karena itu peran guru hanyalah sebagai fasilitator. Materi pelajaran yang sampaikan oleh guru merupakan hal penting dalam proses pembelajaran walaupun siswa diharuskan untuk aktif mencari informasi dari sumber lain mengenai materi ajar yang diajarkan guru. Menurut Agus (2019), dalam penerapan model ini siswa bertindak sebagai facilitator dan juga dituntut untuk mampu berpikir aktif serta kreatif sehingga pertukaran informasi akan lebih mendalam dan menarik yang pada akhirnya akan membuat rasa percaya diri siswa meningkat.

Selain itu, siswa tidak hanya difokuskan pada aspek psikomotorik untuk berkembang dan memperoleh hasil belajar yang baik, tetapi siswa juga harus fokus pada aspek kognitif dan afektif yang juga memiliki peran penting. Selajan dengan Dewi (2018), yang mengatakan bahwa pembelajaran melalui model Student Facilitator And Explaining (SFAE) dapat meningkatkan prestasi belajar siswa yang ditinjau dari 3 ranah yaitu ranah kognitif, afektif dan juga psikomotorik.

Model pembelajaran Student Facilitator And Explaining (SFAE) merupakan model PAIKEM yaitu pembelajaran Aktif, Inovatif, Kreatif, Efektif dan Menyenangkan. PAIKEM disebut juga pembelajaran yang dikembangkan guna membantu siswa dalam mengkonstruk hubungan antara pengetahuan yang baru diperoleh dengan pengalaman yang sudah dimiliki siswa. Selanjutnya siswa diajar mengenai konsep serta pelaksanaan konsep tersebut diluar kelas (Heni, et al., 2017). 


\section{Kesimpulan}

Berdasarkan hasil penelitian dan pembahasan, maka dapat disimpulkan bahwa penerapan model pembelajaran Student Facilitator And explaining (SFAE) berpengaruh terhadap hasil belajar siswa. Terdapat peningkatan hasil belajar siswa Kelas XI IPA MA Negeri Tana Toraja pada materi sistem gerak pada manusia yang dapat dilihat pada perubahan aktivitas siswa yang lebih aktif dalam proses pembelajaran dan pada hasil data deskriptif yang menunjukkan bahwa pada kelas eksperimen dengan penerapan model pembelajaran Student Facilitator And Explaining (SFAE) lebih tinggi dari pada kelas kontrol yang tidak diterapkan model pembelajaran Student Facilitator And Explaining (SFAE).

Penelitian ini hanya dilakukan pada materi sistem gerak pada manusia dengan penerapan model pembelajaran Student Facilitator And Explaining (SFAE) diharapkan pada penelitian selanjutnya dapat melaksanakan penelitian yang serupa pada materi ajar yang berbeda untuk mengukur aspek yang lain atau di jenjang sekolah yang berbeda.

\section{DAFTAR PUSTAKA}

Agus, S. (2019). Cooperative Learning Dan Aplikasi Paikem. Yogyakarta: Pustaka Belajar.

Alpindo, A. (2020). Pengaruh Model Pembelajaran Kooperatif Student Facilitator And Explaining (Sfae) Terhadap Prestasi Belajar Siswa Pada Pokok Bahasan Hidrokarbon di Kelas XI MIPA SMAN 1 Inuman. JOM FTK UNIKS (Jurnal Online Mahasiswa FTK UNIKS), 2(1), 1-10.

Dewi. 2018. Pengaruh Model Pembelajaran Student Facilitator And Explaining (SFAE) Terhadap Terhadap Hasil Belajar Biologi Siswa. Skripsi Tidak Diterbitkan. Jambi: Universitas Islam Negeri Sultan Thaha Saifuddin.

Hamalik, O. (2012). Proses Belajar Mengajar. Jakarta: Bumi Aksara.

Heni, V., D, H. J., \& M, I. S. (2017). Penerapan Metode Student Facilitator And Explaining Berbantuan Media Peta Timbul Terhadap Kemampuan Berpikir Kritis Siswa Pada Materi Sel. JPBIO (Jurnal Pendidikan Biologi), 2 (2), 20-26.

Khausar. (2014). Pengaruh Penerapan Metode Pembelajaran Guru yang Bervariasi Terhadap Peningkatan Hasil Belajar pada Siswa Kelas XI SMA Negeri 1 Labuhanhaji Timur Aceh Selatan. Jurnal Genta Mulia, V (2), 72-85.

Mustikasari, I., Supandi., \& Damayani, A, T. (2019). Pengaruh Model Student Facilitator And Explaining (SFAE) Terhadap Kemampuan Berpikir Kritis. Jurnal Ilmiah Sekolah Dasar, 3 (3), 303-309.

Nopiana, S., \& Mutaqin, J. (2020). Pengaruh Model Pembelajaran Student Facilitator And Explaining (Sfae) Terhadap Motivasi Belajar Siswa Pada Mata Pelajaran IPA Kelas V Di SD Muhammadiyah 5. Bale Aksara, 1 (2), 1-7. 
Prihatiningtyas, N, C., \& Maryam. (2019). Model Student Facilitator And Explaining Terhadap Kemampuan Pemahaman Konsep Matematis. AKSIOMA: Jurnal Program Studi Pendidikan Matematika, 8 (3), 465-473.

Rianti, L \& Nulhakim, L. (2017). Pengaruh Model Student Facilitator And Explaining (SFAE) Terhadap Pemahaman Konsep Siswa Kelas IV Pada Mata Pelajaran IPA. JPSD, 3 (1), 6473.

Riyandi, N., Khausar., Rahman, A, A. (2021). Efektifitas Model Pembelajaran Student Facilitator And Explaining (SFAE) Terhadap Hasil Belajar IPA Siswa Kelas V SD Negeri Krueng Itam Kabupaten Nagan Raya. Jurnal Genta Mulia, XII (1), 54-61.

Shoihim, A. (2014). 68 Model Pembelajaran Inovatif dalam Kurikulum 2013. Yogyakarta: ArRuzz Media.

Sugiyono. (2017). Metode Penelitian Kuantitatif, Kualitatif, dan R\&D. Bandung: Alfabeta.

Zahara, R. (2018). Penerapan Model Pembelajaran Student Facilitator And Explaining (SFAE) Untuk Meningkatkan Hasil Belajar Matematika Siswa Pada Materlogaritma Kelas X1 Sma Negeri 1 Kaway XVI. MAJU: Jurnal Ilmiah Pendidikan Matematika, 5(2), 109-118. 